(were being made) due to the great number of questions regarding doubtful things and obscure, barbarous locutions now current among the people. I included intentionally, with attribution to those who spoke them, if these be known, all of the assertions of which I am aware. I know that there is a tremendous benefit in such an exposition, for should inquirers have doubts about one word or another, they will know the correct from the erroneous by virtue of (the correct word's) being selected. I made that into a single book, and sought to arrange it according to the letters of the alphabet from the beginning and throughout, in order to make searching for words easy and, by virtue of that (arrangement), to aid the investigation of many books, whenever unknown words (are encountered therein), no matter in which language they are written. I know that no book can ever please everyone, but if one who studies certain words in this book is enriched by them, let him know that another (than he) may have need of them. May there be a reward with the Merciful for him who composed this with toil, travail, exertion, and striving, though he knows that it falls short of fulfilling the design, for imperfection encompasses all of the sons of men."

\title{
II. ON THE METHOD OF EDITING THE LEXICON
}

In each of his prefaces, Bar Bahlul tells us that he arranged his lexicon in nearly the best (possible) method and order. However, should you leaf through the work in our edition, you may be greatly surprised at the extent to which it is disordered and confused, as we noted in our preface to the first fascicule (p. v). Again, Bar Bahlul did include prefixed letters at the beginning of words, not, as he says, with the words reduced to their roots; not rarely for these the word is not reduced, but rather is placed in order according to its initial letter. That an immense mass of excerpted things was accumulated by Bar Bahlul himself at one time outside of their proper order does not seem unlikely; yet the interpolators who added new glosses may have been responsible for this confusion, one of whom per century augmented the lexicon with new glosses. There occur excerpts from the writings of Bar Hebraeus, who lived three hundred years after, and also glosses transmitted by 'Jacobite' scribes, whereas Bar Bahlul was an acolyte of the 'Nestorian' sect. There is a question, therefore, concerning what method it is the editor's duty to adopt: If it is his task to restore Bar Bahlul's original work, rejecting extraneous additions, or to present to the judgment of the public the oldest and best copies of the work. Regarding this question a few things might be said.

In his mind, Bar Bahlul did not intend to prepare a new work of his own, but rather he took upon himself the responsibility of writing a compilation of the most useful things from the lexicons of Hunayn, Zachariah of Merv, and Henanišo', and the 
books of other writers, interweaving with these a multitude of glosses for ecclesiastical, medical, and logical terms, adding the names of their authors, as well as expressions of various dialects, of which they were aware, as he himself professes in his preface. From these sources, many glosses, which Bar Bahlul had omitted, were very likely interpolated, given that these are lacking in certain manuscripts. Very likely there is but little interest to know whether these glosses were introduced by Bar Bahlul himself, or by another compiler, and (furthermore) the one who would attempt it would work in vain. Thus it is most expedient to choose the manuscripts (containing) the best versions of the lexicon, and subsequently to note the varying readings of the other manuscripts at the bottoms of the pages. Lagarde himself recommended this approach, writing: ${ }^{30}$ "Those (works) that we name 'Bar 'Ali' and 'Bar Bahlul' are collections of glossaries of unequal value and diverse authorship (produced) over several centuries." He ultimately prescribed the edition of an "integrated corpus of glosses." You should know that the oldest manuscript of the lexicon which has come down to us was written long after the death of Bar Bahlul and contains a great deal of interpolation in the text. You may see also an article in a journal where at one point we discussed this question: Journal Asiatique, January-February I894, I42 and subsequent.

The manuscripts of Bar Bahlul's lexicon are described below. The method I have used in editing is described in the preface to the first fascicule. A new 'Jacobite' manuscript (under the sign $\mathrm{P}$ ) is to be added (to that account), which is kept in the national library in Paris. It came to us from the Orient while the letter $p \bar{e}$ of our edition was in press. Various readings which it offers may be seen from column 1535 (see note 4 beneath that column). It differs a little from the Socinian manuscripts, and contains many additions.

\section{ON THE SOURCES OF THE LEXICON}

Bar Bahlul excerpted the glosses of his lexicon from many books, mentioning both the titles of works and the names of authors. Whatever we know of these we give (here), following the order of the alphabet: ${ }^{31}$

Abba of Kaškar. He became patriarch of the 'Nestorians' in the year 741, 1063:24, , s

\footnotetext{
$3^{30}$ Gesammelte Abhandlungen, 3.

${ }^{31}$ Translator's note: These entries are given following the order in which Duval arranged them, and thus do not follow strictly the order of the alphabet in translation.
} 